\title{
Transitar el vaciado de la Modernidad: los itinerarios por el desierto de Nocilla Dream (2006), de Agustín Fernández Mallo
}

\author{
Sergio CABRERIZO ROMERO \\ Departamento de Humanidades: Filosofía, Lenguaje y Literatura \\ Universidad Carlos III de Madrid \\ cabrerizo.sergio@gmail.com
}

Recibido: $20 / 03 / 2012$

Aceptado: 03/05/2012

\section{Resumen}

Se presenta un análisis de los espacios predominantes en la novela Nocilla Dream (2006), del español Agustín Fernández Mallo. El concepto de ciudad se formula en base a las diferentes fases de la modernidad que cohabitan en los respectivos modelos urbanos de la narración, desde los pueblos fundadores del Oeste Americano hasta Las Vegas, incluyendo prospectivamente la ciudad-nación de Isotope.

Palabras clave: Modernidad, trayectoria, Nocilla Dream, desierto, ciudad prospectiva.

Title: Transiting the emptiness of modernity: the routes throug the dessert of Nocilla Dream (2006), by Agustín Fernández Mallo

\section{Abstract}

It presents an analysis of the predominant spaces in the novel Nocilla Dream (2006), by the spaniard Agustín Fernández Mallo. The city's concept is formulated based on the different phases of modernity that coexist in the respective urban models of the story, since the founding villages of the American West to Las Vegas, including prospectively the Isotope citynation.

Keywords: Modernity, path, Nocilla Dream, desert, prospective city.

\section{Índice}

1. Introducción

2. Nomadismos

3. Direcciones, coordenadas

3.1. El gran desierto americano

3.2. Las micronaciones

3.2.1. La ciudad-nación cubierta

4. Conclusiones 
Un viaje en el espacio equivale a un viaje en el tiempo. (Wallace Stevens, Adagia)

\section{Introducción}

La trilogía narrativa Nocilla ${ }^{1}$ dio nombre a una generación literaria, la llamada "generación nocilla", integrada por escritores jóvenes afines que comenzaban a publicar en los primeros años del nuevo siglo ${ }^{2}$. Sin embargo, la nueva nómina prefiere ser conocida como "generación afterpop" ${ }^{\prime 3}$, como declaración de sus referentes culturales, o "Mutantes"4, para remarcar así su constante predisposición al experimentalismo narrativo. La visibilidad llegó a este grupo del interés, tanto por parte de la crítica como del mercado, de la primera entrega de la trilogía Nocilla: Nocilla Dream (Fernández Mallo 2006), la cual presenta una narrativa caracterizada por la intertextualidad, el microrrelato y el fragmentarismo.

A continuación, se analiza la novela Nocilla Dream desde el avance por los modelos urbanos más representativos de la novela. La narración del espacio se fundamenta en el uso constante de la fragmentación y la multiplicación; lo que parece un puzle narrativo, formado por historias mínimas que comparten itinerarios de vida de naturaleza nómada, crea un sistema en forma de red donde las trayectorias se encuentran y surgen relaciones de continuidad en la asociación de los lugares hacia los que avanza el relato.

La novela parte de espacios que, en todo caso, son representativos de nuestro tiempo histórico: la modernidad, entendida como "proceso cultural e histórico [...] que se articuló sobre la ciencia y sobre la matemática, sobre la objetividad de la ley y sobre el poder del estado, sobre el primado de lo objetivo del conocimiento y de lo objetivo de las normas" (Thiebaut 2004: 11). En el proceso de la modernidad, debe destacarse el desarrollo de nuevos

1 Hago referencia a las tres novelas consecutivas del escritor Agustín Fernández Mallo: Nocilla Dream (2006), Nocilla Experience (2008) y Nocilla Lab (2009).

2 Por solo mencionar a algunos, sin diferenciar géneros literarios: Jorge Carrión, Juan Francisco Ferré, Manuel Vilas, Javier Calvo, Vicente Luis Mora, Eloy Fernández Porta, Javier Fernández y Agustín Fernández Mallo.

${ }^{3}$ El ensayo Afterpop. La literatura de la implosión mediática, del ensayista Eloy Fernández Porta (2007), pone de manifiesto un sentimiento común para este grupo de escritores: la referencialidad constante de su escritura hacia los motivos y estéticas de la cultura contemporánea, aportando una lectura sin prejuicios de la cultura popular, los mass-media y la crítica cultural.

${ }^{4}$ Los autores que aquí se refieren fueron incluidos, entre otros, en la antología de relatos Mutantes. Narrativa española de última generación, con selección y prólogos de Julio Ortega y Juan Francisco Ferré (2007), publicada por la editorial Berenice. Antes, el término mutante había aparecido para referirse a la incipiente narrativa posmodernista en lengua española en La velocidad de las cosas, de Rodrigo Fresán (2002). 
urbanismos, donde cabe pensar una definición moderna de ciudad a partir de los efectos de la revolución industrial y el progreso tecnológico, como "conjunto de actividades cuya configuración [...] depende de la tecnología del movimiento y la comunicación" (Venturi, Scott Brown e Izenour 1972: 103). Partiendo de esta transformación del paradigma de ciudad, originada por un ordenamiento espacial marcado por la aceleración del "movimiento y la comunicación", el viaje que nos propone Fernández Mallo (2006) en Nocilla Dream presenta una visión global del desierto americano, que culmina de "manera prospectiva" (Moreno 2010: 122) con la inclusión de "Isotope Micronation", ciudad-nación sepultada que nos ayuda a reflexionar sobre un posible devenir de los escenarios reales aparecidos en el libro.

\section{Nomadismos}

Los diferentes relatos de la novela se integran sobre el recorrido espacial que se expande en forma de redes de información, simulando el actual paradigma hipertextual de los textos electrónicos; esto es, a modo de enlaces a otros textos con los que comparte alguna relación material; de aquí el interés de abordar la obra desde la perspectiva espacial.

Las configuraciones espaciales de este tipo de narrativa pueden conceptualizarse como "nomadismo estético" (Fernández Mallo 2009b: 184). El término recoge la síntesis del modelo cultural contemporáneo propuesto por Nicolas Bourriaud y el estético de Guy Debord. Bourriaud (2009) contrapone la metáfora cultural del radicante, como vegetal que renueva sus raíces, coordenadas espaciales, según conforma su trayectoria, a la del rizoma (Deleuze y Guattari 1980) sin raíces, sin puntos de localización: "lo radicante toma la forma de una trayectoria, de un recorrido, de una marcha efectuada por un sujeto singular" (Bourriaud 2009: 61); por otro lado, la teoría de la deriva de Debord $^{5}$ (1958-1961) consiste en otorgar categoría estética al movimiento errante y azaroso a través del espacio urbano. Este tipo de travesía, errante y lúdica, puede aplicarse a la dinámica basada en la multiplicidad que propone la novela, en lo que al constante movimiento sobre la coordenada espacial se refiere.

Este tipo de discursos narrativos puede asimilarse a tendencias artísticas y reflexiones más amplias. Cornago (2005: 25) relaciona la dinámica espacial dentro de la estética de lo performativo: "frente al plano temporal dominante en el pensamiento occidental, este

${ }^{5}$ Esta teoría se enuncia en el audiovisual Proyecto nocilla. La película, que puede verse en el blog personal de Agustín Fernández Mallo. El corte al que nos referimos abarca desde el minuto 41 hasta el 44 de dicho largometraje, en Fernández Mallo (2009c). 
acercamiento performativo ilumina un plano material y espacial"; así mismo, la fragmentación espacial que propone este tipo de narrativa incide sobre la participación constructiva de sentido por parte del lector, "convierte a su destinatario no en un consumidor sino en un productor del texto; algo, en fin, no sujeto tampoco a la idea tradicional de intriga que nos pone en la pista de un abandono del paradigma narrativo temporal en beneficio de otro espacial, pues la elaboración de enlaces se produce casi en un marco puramente 'geográfico' o 'cartográfico'" (Abuín González 2006: 71).

\section{Direcciones, coordenadas}

La novela localiza la mayor parte de sus relatos en el desierto de Nevada (Estados Unidos), aportando numerosa información práctica y detallada sobre el lugar, como si tratase de localizar cada historia sobre un mapa. En esta propuesta de viaje, predominan los lugares físicos sobre los virtuales, lo que parece reivindicar la travesía en su más pura materialidad y horizontalidad, más si cabe cuando se trata de trasladar las sensaciones del desplazamiento sobre el terreno desértico.

\subsection{El gran desierto americano ${ }^{6}$}

Los desiertos, como los enfermos, son objetos, aunque vivos, al borde de todo, en proceso de consumación y fundamentalmente delgados. La piel de ambos es blanca-amarilla y subsisten extenuados, aunque siempre encuentran un oasis genético que al final los salva. (Fernández Mallo 2006: 108)

El desierto y la carretera son los no-lugares ${ }^{7}$ más frecuentes en la novela Nocilla Dream. La carretera US50 del desierto de Nevada se convierte en uno de los motivos principales de la novela; la US50, de una longitud de 418 kilómetros, se trata de "la carretera más solitaria de Norteamérica" (Fernández Mallo 2006: 16) y tiene la función de unir dos pueblos casi deshabitados, que cuentan con poco más que unos cuantos supermercados y algún burdel. La mínima presencia de vida y actividad de estos dos pueblos son excepciones y márgenes al vacío de la repetición que impone el desierto. Una primera fase del avance por el vaciado de la modernidad se encuentra en el tránsito por estos pueblos prácticamente abandonados, asentamientos fundadores del mito del Oeste Americano.

Las carreteras, con sus moteles y gasolineras, son el escenario que sirve para presentar condiciones vitales sujetas al concepto de

\footnotetext{
6 Título que da nombre al capítulo 6 del libro Hola América, de J. G. Ballard (1981).

7 En los no-lugares la "principal vocación no es territorial, no consiste en crear identidades singulares, relaciones simbólicas y patrimonios comunes, sino más bien facilitar la circulación" (Augé 2003: 101).
} 
desplazamiento y circulación: la inmigración, el refugio, el turismo. La soledad del desierto se traslada a los relatos y los sujetos, donde la correspondencia entre el entorno y el modo de vida se materializa en un constante tránsito y búsqueda.

El otro gran espacio de la novela es la ciudad de Las Vegas, donde, en contraste con las pequeñas poblaciones del Oeste Americano, se localizan hoy las mayores ambiciones urbanísticas del desierto de Nevada. Las Vegas es el modelo cultural de la mayor concentración de no-lugares, dedicados exclusivamente al consumo de ocio, y responde al modelo posmoderno de la ciudad expandida o ramificación urbana, sin centro reconocible ni espacios públicos de reunión (Dear y Flusty 1998), "un nuevo orden espacial relacionado con el automóvil y la comunicación por autopista" (Venturi, Scott Brown e Izenour 1972: 102). Las Vegas se expande, desordenadamente entre carreteras, debido a las fluctuaciones que impone la circulación de capital: hoteles, capillas, gasolineras, moteles, apartahoteles, burdeles; mientras que, entre caravanas y casetas, los inmigrantes y los desplazados rurales improvisan sus hogares en los márgenes, a la espera de una oportunidad: los habitantes nómadas de las tierras sedientas, como dice uno de los personajes de la novela: "habitar en las ruinas [...] del Imperio" (Fernández Mallo 2006: 48).

\subsection{Las micronaciones}

En este recorrido por el desierto y la modernidad, aparece la ciudadnación prospectiva: la micronación Isotope, que en contraste con el resto de lugares presenta una ubicación desconocida. Esta invención se sustenta sobre la existencia real de las micronaciones.

El fenómeno de las micronaciones surge paradigmáticamente en base a la reivindicación soberana del territorio en función de dos fenómenos modernos: la ocupación por varias personas de bases militares abandonadas, como es el caso del fundador Principado de Sealand en aguas internacionales o el microestado independiente de Christiania dentro de la ciudad de Copenhage (Dinamarca), y la reivindicación de territorios fronterizos, como el Reino de Ergaland \& Vargaland. La posibilidad de la existencia de las micronaciones se efectúa sobre los vacíos legislativos existentes sobre determinados territorios físicos, partiendo habitualmente de proyecciones utópicas de movimientos de carácter político o social, como el hippie durante los años sesenta y setenta, reivindicaciones de carácter histórico o cultural o creaciones artístico-literarias ${ }^{8}$. La micronación, por tanto, se levanta como una posibilidad de subversión del orden nacional

\footnotetext{
${ }^{8}$ Para ampliar información sobre las micronaciones, vid.: http://www.angelfire.com/nv/micronations/enter.html
} 
desde sus propias leyes, reivindicando la soberanía del individuo frente a la del Estado-Nación.

\subsubsection{La ciudad-nación cubierta}

La inclusión de la prospectiva micronación Isotope en el universo narrativo de Nocilla Dream contrasta con la ambientación de los otros relatos, así, mientras que Isotope se presenta aislado, pues sucede en una localización indeterminada del desierto, el resto está presentado desde su ubicación exacta, lo que lo pone en relación con los otros lugares.

Isotope, con 178 ciudadanos, se asienta bajo una extensión de $77.000 \mathrm{~m}^{2}$ del desierto de Nevada, en lo que fue el Centro de Recogida de Residuos Radiactivos del Gobierno de los Estados Unidos. Esta micronación, que se encuentra fortificada, cuenta con los servicios necesarios para autoabastecerse, mediante la modificación del desierto para conseguir desarrollar sus cultivos y la producción de ganado, y la instalación de transformadores de energía, todo mediante un software que controla la superficie; el desarrollo hipertecnológico les permite abandonar la superficie desértica y controlar todas las tareas desde el subsuelo, lo que además, dadas las enormes proporciones de la construcción, les ofrece la posibilidad de vivir incomunicados de los demás y "pasar hasta un mes sin verse una sola vez" (Fernández Mallo 2006: 81).

Como señalan Moreno y Palibrik (2011: 126) en su clasificación de ciudades prospectivas, "la claustrofobia de las ciudades subterráneas se relaciona con las extrañas costumbres sociales de los ciudadanos". Esta extraña costumbre se relaciona con una morbosa práctica en Isotope: debido a su breve existencia, solo diez años, y a sus desproporcionadas dimensiones, realizan apuestas todas las semanas sobre quién morirá antes, lo que reporta al acertante el premio de quedarse con el patrimonio del fallecido.

La inserción de Isotope sirve para subrayar la soledad del individuo en los modelos de espacios urbanos que se presentan. En este caso, la condición extrema de soledad y aislamiento se origina de la elección individual, dándosenos a conocer los orígenes de uno de los habitantes de Isotope antes de su entrada a vivir en la micronación. Del resto de relatos de la novela que suceden fuera de la micronación, se desprende la melancolía y frustración de los personajes ante los tiempos históricos inciertos que les toca vivir, los cuales imponen en todos los casos la necesidad de puesta en circulación, de movimiento constante, como símbolo de una incesante búsqueda de anhelos no logrados. 


\section{Conclusiones}

La existencia de la ciudad prospectiva, Isotope, introduce la reflexión más allá del tono realista con que se nos presentan los escenarios de la novela. Isotope se nos presenta como una ciudad búnker que permite, por sus dimensiones, vivir aislado del resto de sus conciudadanos, debido al alto nivel de desarrollo de las comunicaciones y el movimiento, iluminadoras de la distribución espacial hacia la que avanza la modernidad.

Isotope se sirve de lugares abandonados para abolir las relaciones sociales, incluso para establecer su propia nación independiente, derivada de la capacidad de autonomía de las ciudades frente al resto del territorio. En estos asentamientos inventados, la necesidad individualista se traduce en comunidades privadas, privilegiadas e hiper-tecnologizadas.

Esta lectura propuesta se levanta sobre la analogía de realidades, entre el desierto y la ciudad, según se enuncia en la novela: "todos los desiertos son el mismo [y también por lo tanto las ciudades que sepultan, en las que habiendo desaparecido calles, plazas y autopistas ya sólo existe una dirección reconocible: la que define el vector de gravedad que apunta al centro de una tierra cada vez más lejana]" (Fernández Mallo 2006: 144). Dos caras de una misma moneda, donde los sujetos responden a dinámicas vitales asociadas a identidades espaciales, determinadas por "topologías de acceso o exclusión, por la pertinencia o la expulsión de territorios" (Broncano 2009: 39).

Para acabar, cabe destacar el hecho de que todos los espacios narrativos expuestos cumplen con las características de ser lugares inhóspitos, impersonales y en procesos de continua transformación: una estética del lugar solitario, impersonal y errante, donde los individuos tratan aislados de sobrevivir al medio hostil, sin confiar en la empresa común del progreso como ideal de la modernidad. 


\section{Bibliografía}

ABUÍN GONZÁLEZ, Anxo (2006): Escenarios del caos: entre la hipertextualidad y la performance en la era electrónica. Valencia: Tirant lo Blanch.

AUGÉ, Marc (2003): El tiempo en ruinas. Barcelona: Gedisa.

BALLARD, J. G. (1981): Hola América. Barcelona: Minotauro, 2003.

BOURRIAUD, Nicolas (2009): Radicante. Buenos Aires: Adriana Hidalgo.

BRONCANO, Fernando (2009): La melancolía del ciborg. Barcelona: Herder.

CORNAGO, Óscar (2005): Resistir en la era de los medios. Estrategias performativas en literatura, teatro, cine y televisión. Madrid / Frankfurt: Iberoamericana / Vervuert.

DEAR, Michael; y FLUSTY, Steve (1998): "Postmodern urbanism". Annals of the Association of American Geographers, vol. 88, núm. 1, pp. 50-72.

DEBORD, Guy (1958-1961): Internacional situacionista, vol. I: La realización del arte. Madrid: Literatura Gris, 1999.

DELEUZE, Gilles; y GUATTARI, Félix (1980): Mil mesetas. Capitalismo y esquizofrenia. Valencia: Pre-Textos, 2010.

FERNÁNDEZ MALLO, Agustín (2006): Nocilla Dream. Barcelona: Candaya.

- (2008): Nocilla Experience. Madrid: Alfaguara, 2008.

- (2009a): Nocilla Lab. Madrid: Alfaguara.

- (2009b): Postpoesía. Hacia un nuevo paradigma. Barcelona: Anagrama.

- (2009c): el hombre que salió de la tarta. Blog de Agustín Fernández Mallo [en línea]. Alfaguara: Tres Tristes Tigres, 4/10/2009. En: http://blogs.alfaguara.com/fernandezmallo/proyecto-nocilla-lapelicula/ [Consulta: 3/01/2012].

FERNÁNDEZ PORTA, Eloy (2007): Afterpop. La literatura de la implosión mediática. Córdoba: Berenice.

FRESÁN, Rodrigo (2002): La velocidad de las cosas. Barcelona: Mondadori.

MORENO, Fernando Ángel (2010): Teoría de la literatura de ciencia ficción: Poética y retórica de lo prospectivo. Vitoria: Portal Editions.

MORENO, Fernando Ángel; y PALIBRK, Ivana (2011): "La ciudad prospectiva" [en línea]. Ángulo Recto. Revista de estudios sobre la ciudad como espacio plural, vol. 3, núm. 2, pp. 119-131. En: http://www.ucm.es/info/angulo/volumen/Volumen03-2/varia01.htm [Consulta: 03/01/2012]. ISSN: 1989-4015. DOI: http://dx.doi.org/10.5209/rev ANRE.2011.v3.n2.37584

ORTEGA, Julio; y FERRÉ, Juan Francisco (2007): Mutantes. Narrativa española de última generación. Córdoba: Berenice.

THIEBAUT, Carlos (2004): "La identidad extrañada: mapas, tiempos y figuras" [en línea]. Boletín de Estética, núm. 1, pp. 3-20. En: http://www.boletindeestetica.com.ar/boletines/Boletin.Estetica.1.pdf [Consulta: 20/05/2012]. ISSN: 1668-7132.

VENTURI, Robert; IZENOUR, Steven; y SCOTT BROWN, Denise (1972): Aprendiendo de Las Vegas: el simbolismo olvidado de la forma arquitectónica. Madrid: Gustavo Gili, 2000. 